\title{
Longitudinal Statistical Analysis of Weight, Volume, Surface Area and Circumferential Measurements for a Female Bariatric Population
}

\author{
David B. STEFAN ${ }^{1}$, David A. GILBERT ${ }^{2}$ \\ ${ }^{1}$ Novaptus Systems Inc., Chesapeake, VA, USA; \\ ${ }^{2}$ The Hague Plastic and Cosmetic Surgery Center, Norfolk, VA, USA \\ DOI: 10.15221/15.068 http://dx.doi.org/10.15221/15.068
}

\section{Introduction}

One "rule of thumb" for evaluating a successful outcome for a gastric bypass or sleeve bariatric surgical procedure is to monitor the subject's "\% Excess Weight Loss." In general, the desired goal is to achieve $75 \%$ "Excess Weight Loss" around 1 year after their surgical procedure. This figure is not exact. There may be a number of reasons why a particular patient may not achieve this outcome. These could range from certain medical conditions or medicinal regimes to a lack of embracing the lifestyle changes that are required to achieve the optimal outcome after surgery. Nonetheless it is a benchmark commonly used in practice today. What is not known is the relationship, if any, between weight loss and the physical changes to the individual's body shape and their measurements, including volume and surface area as it undergoes this dramatic transition.

3D booth type scanners have been utilized to document morbidly obese individuals prior to, and after bariatric surgery. Morbidly obese individuals are scanned before prior procedure. These individuals receive a printout that contains common circumferential measurements, such as chest, waist, hips, etc. The measurement printout acts as a reference, helping the individual understand their measurement changes over time as they return for post-operative follow-up appointments and repeat scans.

Multiple measurement profiles can be applied to the $3 \mathrm{D}$ scan. These include measurements for volume and surface area, as well as a torso slice function which can be exploited for various purposes. These measurements, heretofore not readily available, allow for multi-dimensional analysis of the changing shape of the individual undergoing massive weight loss.

A statistical analysis of longitudinal data from a de-identified and aggregated female bariatric population was performed that compared weight and anthropometric data collected from 3D booth scanners pre-operatively to such data collected post-operatively at 3,6 and 12 month intervals. Comparisons were made between weight loss, torso volume loss, torso surface area loss and circumferential measurement changes. Descriptive statistics were produced for each time interval.

These individuals were selected at random for each interval, including the interval between the 6 month postoperative scan and the 12 month postoperative scan. In addition to these random selections, a group of 50 females comprise an additional 12 month "overall change" group, where their initial weights were compared with their weight at the end of the 12 month period to determine their actual "\% Excess Weight Loss."

\section{Background}

One might initially suppose that all that was needed to monitor and evaluate a bariatric surgical outcome would be to simply record the progressive weight loss of the particular individual. This is important, but it doesn't tell the whole story. What is needed is a reference to which the individual's weight loss can be meaningfully compared.

One common reference method is to use actuarial tables set forth by insurance companies. Tables such as these contain height and gender, and can be furthered subdivided by age and body frame type. All contain recommended body weights for a particular height. One common reference is the Metropolitan Life Insurance Company's 1959 actuarial tables ${ }^{1}$. This appears in Table 1. 


\begin{tabular}{|l|l|l|l|}
\hline Height & Small Frame & Medium Frame & Large Frame \\
\hline $4^{\prime} 09^{\prime \prime}$ & $90-97$ & $94-106$ & $102-118$ \\
\hline $4^{\prime} 10^{\prime \prime}$ & $92-100$ & $97-109$ & $105-121$ \\
\hline $4^{\prime} 11^{\prime \prime}$ & $95-103$ & $100-112$ & $108-124$ \\
\hline $5^{\prime} 00^{\prime \prime}$ & $98-106$ & $103-115$ & $111-127$ \\
\hline $5^{\prime} 01^{\prime \prime}$ & $101-109$ & $106-118$ & $114-130$ \\
\hline $5^{\prime} 02^{\prime \prime}$ & $104-112$ & $109-122$ & $117-134$ \\
\hline $5^{\prime} 03^{\prime \prime}$ & $107-115$ & $112-126$ & $121-138$ \\
\hline $5^{\prime} 04^{\prime \prime}$ & $110-119$ & $116-131$ & $125-142$ \\
\hline $5^{\prime} 05^{\prime \prime}$ & $114-123$ & $120-135$ & $129-146$ \\
\hline $5^{\prime} 06^{\prime \prime}$ & $118-127$ & $124-139$ & $133-150$ \\
\hline $5^{\prime} 07^{\prime \prime}$ & $122-131$ & $128-143$ & $137-154$ \\
\hline $5^{\prime} 08^{\prime \prime}$ & $126-136$ & $132-147$ & $141-159$ \\
\hline $5^{\prime} 09^{\prime \prime}$ & $130-140$ & $136-151$ & $145-164$ \\
\hline $5^{\prime} 10^{\prime \prime}$ & $133-144$ & $140-155$ & $149-169$ \\
\hline
\end{tabular}

Table 1: Metropolitan Life Insurance Company, 1959 Reference Weight Chart for Females

Other sets of reference weight charts include those provided by the military, or by a government health agency. Table 2 displays the Reference Weight Chart for Females from the U.S. Army².

\begin{tabular}{|l|l|l|l|l|}
\hline Height & $17-20$ Yrs. & $21-27$ Yrs. & $28-39$ Yrs. & $40+$ Yrs. \\
\hline $4^{\prime} 10^{\prime \prime}$ & 104 & 107 & 110 & 113 \\
\hline $4^{\prime} 11^{\prime \prime}$ & 107 & 110 & 114 & 117 \\
\hline $5^{\prime} 00^{\prime \prime}$ & 111 & 114 & 117 & 121 \\
\hline $5^{\prime} 01^{\prime \prime}$ & 115 & 118 & 121 & 125 \\
\hline $5^{\prime} 02^{\prime \prime}$ & 119 & 123 & 126 & 130 \\
\hline $5^{\prime} 03^{\prime \prime}$ & 123 & 126 & 130 & 134 \\
\hline $5^{\prime} 04^{\prime \prime}$ & 126 & 130 & 134 & 138 \\
\hline $5^{\prime} 05^{\prime \prime}$ & 130 & 134 & 138 & 142 \\
\hline $5^{\prime} 06^{\prime \prime}$ & 135 & 139 & 143 & 147 \\
\hline $5^{\prime} 07^{\prime \prime}$ & 139 & 143 & 148 & 151 \\
\hline $5^{\prime} 08^{\prime \prime}$ & 143 & 147 & 151 & 156 \\
\hline $5^{\prime} 09^{\prime \prime}$ & 147 & 151 & 155 & 160 \\
\hline $5^{\prime} 10^{\prime \prime}$ & 151 & 156 & 160 & 165 \\
\hline
\end{tabular}

Table 2: Reference Weight Chart for Females - U.S. Army

For purposes of this paper's analysis, the reference used to determine recommended body weight was from the North American Association for the Study of Obesity - Females ${ }^{3}$ as presented in Table 3. This is a simple table. It contains height, in inches, ranging from 58 inches to 72 inches. A recommended weight is associated with each height increment. This weight has been averaged with all the participants, regardless of age. If one wishes to use a more detailed recommended weight chart, it would be a simple table look-up process, though one would need to know the age of the individual in question and possibly gauge the body frame type. 


\begin{tabular}{|l|l|}
\hline Height & All Ages \\
\hline $4^{\prime} 10^{\prime \prime}$ & 114 \\
\hline $4^{\prime} 11^{\prime \prime}$ & 118 \\
\hline $5^{\prime} 00^{\prime \prime}$ & 121 \\
\hline $5^{\prime} 01^{\prime \prime}$ & 124 \\
\hline $5^{\prime} 02^{\prime \prime}$ & 128 \\
\hline $5^{\prime} 03^{\prime \prime}$ & 131 \\
\hline $5^{\prime} 04^{\prime \prime}$ & 134 \\
\hline $5^{\prime} 05^{\prime \prime}$ & 137 \\
\hline $5^{\prime} 06^{\prime \prime}$ & 140 \\
\hline $5^{\prime} 07^{\prime \prime}$ & 144 \\
\hline $5^{\prime} 08^{\prime \prime}$ & 147 \\
\hline $5^{\prime} 09^{\prime \prime}$ & 150 \\
\hline $5^{\prime} 10^{\prime \prime}$ & 153 \\
\hline $5^{\prime} 11^{\prime \prime}$ & 157 \\
\hline $6^{\prime} 00^{\prime \prime}$ & 161 \\
\hline
\end{tabular}

Table 3: Reference Weight Chart used in this Paper.

North American Association for the Study of Obesity - Females

Figure 1 shows an example of how to calculate "Excess Weight". Once "Excess Weight" has been determined, "\% Excess Weight" can then be derived.

The individual in this example presents with a weight of 260 pounds and she is 68 inches tall. Looking at the table one can find that her recommended weight is 147 pounds. Subtracting 147 pounds from 260 pounds yields 113 pounds. That is her excess weight. To find her "\% Excess Weight" one divides the excess weight by the current weight. Therefore $113 / 260$ is .43 , or $43 \%$. That is to say that this individual's weight is $43 \%$ more than the recommended weight for a female with the same height.

To achieve the desired goal of $75 \%$ Excess Weight Loss" at the end of 1 year after surgery she would have to lose $0.75 * 113$, or around 85 pounds.

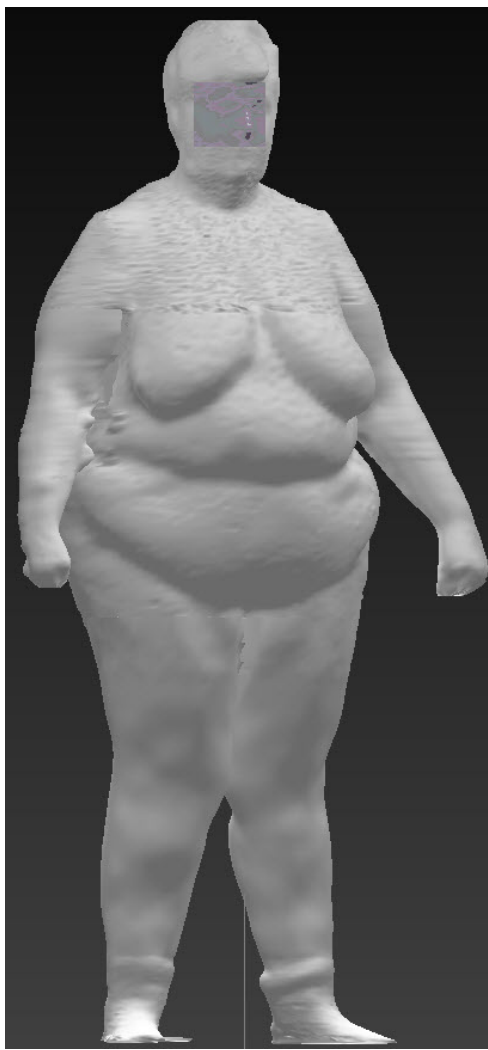

$$
\begin{aligned}
& \text { Initial Weight } \\
& \text { and Height: } \\
& 260 \mathrm{lbs} \\
& 68 \text { in } \\
& \text { Reference } \\
& \text { Weight: } \\
& 147 \text { lbs } \\
& \\
& \text { Excess } \\
& \text { Weight: } \\
& 113 \text { lbs } \\
& \\
& \% \text { Excess } \\
& \text { Weight: } \\
& 113 / 260 \\
& \text { or } \\
& 43 \% \\
& 75 \% \\
& \text { Excess } \\
& \text { Weight } \\
& \text { Loss: } \\
& 85 \text { lbs }
\end{aligned}
$$

Figure 1. Initial Conditions: Calculating Excess Weight and \% Excess Weight 
It is common in a bariatric practice to have multiple pre-operative consultations. The first is generally an orientation, the next might be for qualification, etc. Once the individual has moved beyond the numerous gates and has gained clearance for the procedure, they must undergo what is termed a "History and Physical." This is where all their medical history is noted, and their bloodwork is taken. This is the point where the individuals are scanned and weighed preoperatively.

Individuals that have had the surgical procedure return periodically for follow-up visits. These can range from 1 week, 1 month, 3 months, 6 months, 9 months and 1 year, and even beyond. Postoperative scanning for these individuals begins at the 3 month visit. They are also scanned at their 6 month and 1 year post-operative visits. It should be noted that these visit intervals are not exact and precise. In actuality, a 6 month post-op visit might be 5 months or 7 months after surgery.

\section{Methodology}

The height of the individual, initial weight, weight to lose and "\% Excess Weight" recording and calculations are determined prior to the surgery. These are measurements that are not associated with the 3D body scanner.

The individual is then scanned preoperatively. The same measurement templates were applied to the pre-operative and repetitive post-operative 3D body models depending on gender.

Two types of measurement templates were used to extract measurements from the individual 3D body models. The first template extracted common circumferential measurements. This is the profile that is gender specific. The female template contains two additional measurements which are of little interest to males. They are the "Bust Contoured" and "Seat" measurements. This measurement template produced measurements in inches. As this paper concerns a female bariatric population, the circumferential measurements extracted by the female measurement template are listed in the Figure 2.

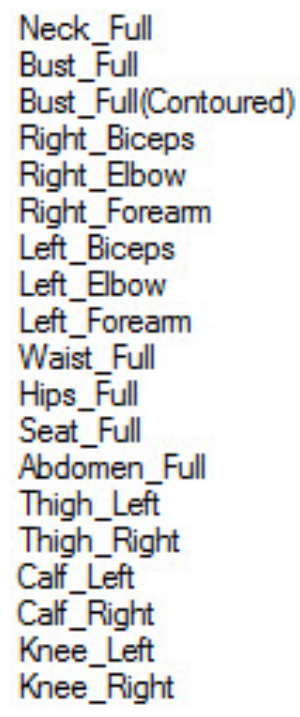

Figure 2. Circumferential Measurements extracted from the Female Bariatric Population

The second measurement template applied to the 3D body models consisted of a profile that includes torso volume and torso surface area components as well as the height of particular measurements. Included in this profile is a routine that determines the torso height, and produces $1 \mathrm{~cm}$ slice measurements of the torso. For each slice, volume and surface area are given. This information can be combined to determine overall torso volume and torso surface area. These elements then produce the Torso Volume/Torso Surface Area Ratio, or "TVSA Ratio", a measurement of how much "space" an individual occupies, regardless of the individual's weight. It uses the torso, including hips and buttocks but not the head as a proxy for the entire body. This measurement template is not gender specific. 
When applied, each measurement template produces a comma delimited file that can be imported into a spreadsheet program, such as Excel or others. Customized macros were constructed to manipulate the measurement data, calculate various formulas and format the result. Generally, both templates are used to produce a commercial product known as a "Weight Loss Storybook." The Storybook documents the weight loss progress and body shape transition of each individual as tracked by the 3D body scanner.

The components of this measurement extraction profile are listed in Figure 3.

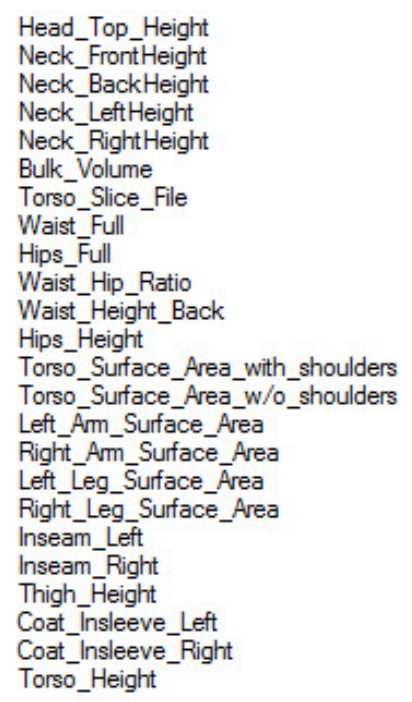

Figure 3. Torso Slice, Torso Height, Torso Surface Area, Torso Volume and Heights of Certain Measurements are produced using this Extraction Profile

An example of an individual's longitudinal spreadsheet is shown in Table 4.

\begin{tabular}{|c|c|c|c|c|c|c|c|c|c|c|}
\hline Measurements, Inches & Pre-op & 11.14.14 & Change & 2.13 .15 & Change & 5.14 .15 & Change & 8.14 .15 & Change & Overall Chg \\
\hline Neck_Full & 17.73 & 16.46 & -1.28 & 15.77 & -0.68 & 14.90 & -0.88 & 14.50 & -0.39 & -3.23 \\
\hline Bust_Full & 56.63 & 48.54 & -8.08 & 45.19 & -3.35 & 41.35 & -3.84 & 38.87 & -2.48 & -17.75 \\
\hline Bust_Full(Contoured) & 56.84 & 49.01 & -7.83 & 45.77 & -3.25 & 41.14 & -4.63 & 39.24 & -1.90 & -17.60 \\
\hline Right_Biceps & 15.57 & 14.86 & -0.71 & 13.70 & -1.15 & 13.79 & 0.09 & 11.59 & -2.20 & -3.98 \\
\hline Right_Elbow & 12.61 & 11.88 & -0.73 & 11.12 & -0.76 & 10.90 & -0.21 & 10.32 & -0.58 & -2.29 \\
\hline Right_Forearm & 12.15 & 11.16 & -0.98 & 10.68 & -0.49 & 10.55 & -0.13 & 10.15 & -0.40 & -2.00 \\
\hline Left_B̈iceps & 15.75 & 14.67 & -1.08 & 13.72 & -0.96 & 13.81 & 0.10 & 11.62 & -2.19 & -4.13 \\
\hline Left_Elbow & 12.47 & 11.80 & -0.66 & 10.99 & -0.82 & 10.47 & -0.52 & 10.32 & -0.14 & -2.14 \\
\hline Left_Forearm & 12.00 & 10.95 & -1.06 & 10.59 & -0.36 & 9.97 & -0.63 & 9.92 & -0.05 & -2.08 \\
\hline Waist_Full & 53.33 & 47.48 & -5.86 & 41.63 & -5.85 & 37.34 & -4.29 & 34.65 & -2.70 & -18.68 \\
\hline Hips_Full & 58.45 & 52.49 & -5.96 & 47.54 & -4.95 & 44.01 & -3.53 & 42.08 & -1.93 & -16.37 \\
\hline Seat_Full & 57.78 & 52.01 & -5.77 & 47.32 & -4.69 & 43.90 & -3.42 & 42.04 & -1.86 & -15.74 \\
\hline Abdomen_Full & 58.01 & 50.97 & -7.04 & 45.37 & -5.59 & 41.84 & -3.53 & 41.69 & -0.15 & -16.32 \\
\hline Thigh_Left & 27.45 & 24.63 & -2.82 & 22.57 & -2.06 & 21.90 & -0.68 & 21.69 & -0.20 & -5.76 \\
\hline Thigh_Right & 27.74 & 25.07 & -2.67 & 23.00 & -2.07 & 22.18 & -0.82 & 22.00 & -0.18 & -5.73 \\
\hline Calf_Left & 16.96 & 16.05 & -0.91 & 15.22 & -0.83 & 14.47 & -0.75 & 13.81 & -0.66 & -3.14 \\
\hline Calf_Right & 16.88 & 16.02 & -0.86 & 15.47 & -0.56 & 14.43 & -1.04 & 13.93 & -0.50 & -2.95 \\
\hline Knee_Left & 16.69 & 15.28 & -1.40 & 14.84 & -0.44 & 14.28 & -0.56 & 14.28 & 0.00 & -2.41 \\
\hline Knee_Right & 16.74 & 15.35 & -1.39 & 15.20 & -0.15 & 14.32 & -0.88 & 14.20 & -0.12 & -2.54 \\
\hline Torso Height $\mathrm{cm}$ & 70.00 & 68.00 & -2.00 & 68.00 & 0.00 & 68.00 & 0.00 & 68.00 & 0.00 & -2.00 \\
\hline Torso Volume cc & 89725.40 & 69191.00 & -20534.40 & 58982.10 & -10208.90 & 48932.90 & -10049.20 & 43283.50 & -5649.40 & -46441.90 \\
\hline Torso Surface Area & 9106.90 & 7752.10 & -1354.80 & 7445.00 & -307.10 & 6685.00 & -760.00 & 6598.70 & -86.30 & -2508.20 \\
\hline BariPlex & 7.10 & 7.62 & 0.51 & 8.58 & 0.96 & 9.29 & 0.71 & 10.37 & 1.08 & 3.26 \\
\hline TVSA Ratio & 9.85 & 8.93 & -0.93 & 7.92 & -1.00 & 7.32 & -0.60 & 6.56 & -0.76 & -3.29 \\
\hline Weight & 269.00 & 221.00 & -48 & 193.00 & -28 & 166.00 & -27.00 & 149.00 & -17.00 & -120.00 \\
\hline
\end{tabular}

Table 4: An Individual Longitudinal Spreadsheet comprised of a Scan Series 
Close examination of Table 4 indicates how the two templates are processed and presented. The upper half of the spreadsheet contains circumferential measurements taken before surgery, and subsequent 3, 6 month and 1 year post-operative intervals. Columns next to the scan date indicate changes from each progressive scan. The final column indicates the overall change between the preoperative scan and the final post-operative scan, which is usually around 1 year after the surgery date.

The individuals who underwent the surgical procedure generally pay close attention to this part of their Storybook, and understandably so.

The lower half of the spreadsheet is much more interesting. It contains information that was previously unavailable. This is the multidimensional information generated by the raw information produced by applying the second measurement extraction profile shown in Figure 3 to the same 3D body model.

The torso slice file, with the help of spreadsheet macros produces Torso Height in $\mathrm{cm}$, Torso Volume in $\mathrm{cc}$ and Torso Surface Area in $\mathrm{cm}$ squared. The Torso Height was defined by the scanner measurement software as being the distance from the "Back of Neck" body landmark to the "Crotchpoint" location. The "Crotchpoint" location is a "touchy" measurement due to the way various scanners determine the separation between the torso and the individual's legs. It often needs to be manually adjusted. In theory, the torso height of an individual should be fixed. However, the author has noted situations where the massive amount of weight loss has apparently decreased pressure on the spinal column or legs, resulting in changes in posture. Some small variations between scans are therefore inevitable. One must note, however, that the torso height directly affects the number of torso slices produced, which will in turn have impact on both the Torso Surface Area and Torso Volume calculations.

Previous papers have been published about the BariPlex and the TVSA Ratio ${ }^{5}$. The TVSA ratio uses the Torso Volume divided by the Torso Surface area. There is a fundamental relationship between obesity and the TVSA ratio. It is clearly evidenced in the longitudinal spreadsheet example in Table 4. At the individual's preoperative weight, the TVSA is quite high. As massive weight loss occurs, the TVSA declines significantly. At the individual's initial weight, the volume is quite large relative to their surface area. As the individual loses weight, the volume begins to reduce more rapidly than the surface area change. A good analogy of this would be to visualize a ream of individual sheets of paper stacked together to form a cube (decreasing faster in $\mathrm{cc}$ than $\mathrm{cm}$ squared). As the sheets of paper are rapidly removed, the volume reduces at a greater rate than the surface area. Finally, picture a single sheet of paper. It has a large surface area (front and back of the sheet of paper), but a very small volume (the front and back of the sheet of paper multiplied by its thickness).

The Bariplex is similar to the TVSA, but incorporates the individual's torso height. The formula is the individual's torso height divided by TVSA Ratio. This allows longitudinal comparisons to be made sequential scans of the same individua, or on a collective basis with other individuals that have the same torso height.

There is a scale associated with the Bariplex that indicates the degree of adiposity of an individual. In essence, this is a measurement of how much "space" an individual occupies, without regard to weight or overall height. Morbidly obese individual can track the changes to their Bariplex as they lose weight and move into the Extremely Obese, Overweight, Slightly Overweight and Proportionally Ideal subcategories within the generalized Bariplex Scale.

As can be seen, Table 4 contains a multidimensional spreadsheet that tracks individual measurement changes over time and encompasses the preoperative body measurements and preoperative weight. Postoperative measurements extracted by the two measurement templates are formatted such that comparisons between the measurements of each scan can be made. Measurements are added with each sequential postoperative scan. Each successive set of scan measurements are compared with the previous scan measurements and are also compared with the pre-operative scan measurements. 3 months scans for individuals can be aggregated and analyzed as a group. One does not have to wait for a series of individual scans to be completed to use this data.

These individual longitudinal spreadsheets form the basis of the aggregated data that was analyzed. Several different scanner models from two different manufacturers have been used over the years to collect and process data. If a SizeStream scanner was used to collect the 3D body models, it was converted to be measured using TC2 measurement software. The SizeStream body model is output 
in .obj format. The TC2 Data Converter Utility was utilized to create a TC2 .bin file, and the TC2 measurement software was used for measurement extraction. The measurement extraction profiles were created using the MEP editor offered within the TC2 software. If there were any obvious measurement errors (such as the "Crotchpoint" determination, armpit location or each olecranon location) the measurements were manually moved by the author and the subsequent TC2 rbd file was saved for processing. This was true regardless of which scanner vendor was utilized to acquire the 3D body model.

\section{Results}

The results on this analysis are presented in several sections. The first set of data that is presented is a statistical analysis of the initial weight of preoperative females that comprised the "Overall Change Group." This is depicted in Table 5.

\begin{tabular}{|c|c|c|c|c|c|c|}
\hline & $\begin{array}{c}\text { Initial } \\
\text { Weight }\end{array}$ & Height & BMI & $\begin{array}{c}\text { Reference } \\
\text { Weight }\end{array}$ & $\begin{array}{c}\text { Excess } \\
\text { Weight }\end{array}$ & $\begin{array}{c}\% \text { Excess } \\
\text { Weight }\end{array}$ \\
\hline Average & 267 & 65 & 45 & 138 & 129 & .47 \\
\hline Median & 260 & 66 & 43 & 40 & 123 & .47 \\
\hline Std. Dev & 48 & 3 & 7 & 9 & 45 & .07 \\
\hline MIN & 201 & 58 & 34 & 118 & 72 & .34 \\
\hline MAX & 472 & 70 & 68 & 153 & 319 & .68 \\
\hline
\end{tabular}

Table 5: Initial Weight Statistics for a Female Bariatric Population Comprising the "Overall Change Group"

The number of females in this population was 50 . They were chosen since they had complete longitudinal charts out to 1 year of periodic scans, and their weight was recorded prior to each scan. Some of these selections were part of the population used to evaluate 3 month and 6 month measurement statistics presented below. We will come back to this initial information and compare this to the overall measurement and weight recording results of the "Overall Change Group" at the 1 year time interval.

As one may inspect from Table 5, the average weight of the female population was 267 pounds, and the average height of the population was 65 inches. This data set is slightly skewed as the median is less than the average. This was because one individual within the population had an initial weight of 472 pounds, which had an effect on the average. However the average \% Excess Weight and the median \% Excess Weight are identical, indicating that this set of data is representative of a greater population.

Table 6 depicts the changes a population of female bariatric patients underwent as scanned 3 months after their surgical procedure. Please note that these are changes between the preoperative measurements and the 3 month postoperative measurements and not the actual measurements themselves. This set was comprised of 120 randomly selected females.

Table 6 indicates the average loss per measurement extracted as well as its median and standard deviation. This is a very diverse set of data, yet the average and median for each measurement appears to be well behaved. Importantly, the changes in Torso Height between the preoperative and 3 month postoperative scan groups are minimal. This means that changes for Torso Volume and Torso Surface Area can be considered consistent and are valid for comparison between scan intervals.

The average individual in the female population lost around 50 pounds over a 3 month time frame. She also lost $15939 \mathrm{cc}$ of her Torso Volume and 907 square $\mathrm{cm}$ of Torso Surface Area. 


\begin{tabular}{|l|c|c|c|}
\hline Measurements, Inches & Average Loss & Median Loss & std dev \\
\hline Neck_Full & -1.80 & -1.32 & 1.96 \\
\hline Bust_Full & -5.14 & -5.09 & 2.34 \\
\hline Bust_Full(Contoured) & -5.25 & -5.30 & 2.68 \\
\hline Right_Biceps & -1.77 & -1.65 & 1.21 \\
\hline Right_Elbow & -1.01 & -0.88 & 1.11 \\
\hline Right_Forearm & -1.14 & -1.07 & 1.04 \\
\hline Left_Biceps & -1.74 & -1.68 & 1.06 \\
\hline Left_Elbow & -1.08 & -1.02 & 1.02 \\
\hline Left_Forearm & -1.10 & -0.94 & 0.81 \\
\hline Waist_Full & -5.83 & -5.82 & 1.69 \\
\hline Hips_Full & -5.98 & -5.81 & 1.41 \\
\hline Seat_Full & -5.96 & -5.79 & 1.49 \\
\hline Abdomen_Full & -6.33 & -6.04 & 2.30 \\
\hline Thigh_Left & -3.08 & -2.89 & 1.37 \\
\hline Thigh_Right & -3.16 & -3.03 & 1.45 \\
\hline Calf_Left & -1.27 & -1.25 & 0.53 \\
\hline Calf_Right & -1.30 & -1.27 & 0.56 \\
\hline Knee_Left & -1.33 & -1.30 & 0.98 \\
\hline Knee_Right & -1.39 & -1.31 & 1.05 \\
\hline Torso Height cm & & & \\
\hline Torso Volume cc & -15939.23 & -16183.85 & 5925.21 \\
\hline Torso Surface Area & -907.11 & -958.15 & 402.04 \\
\hline BariPlex & 0.82 & 0.81 & 0.37 \\
\hline TVSA Ratio & -0.97 & -0.93 & 0.35 \\
\hline Weight & -50.87 & -49.00 & 13.03 \\
\hline & & & \\
\hline & & 0.00 & 1.74 \\
\hline
\end{tabular}

Table 6: Three Month Postoperative Measurement Changes

Table 7 offers the changes that a population of female bariatric individuals underwent as scanned 6 months after their surgical procedure. Please note that these are the sequential changes between the 3 month aggregate data and the 6 month aggregate data. The information displayed is not the overall changes between the 6 month data and the preoperative data. This set was comprised of 79 randomly selected females.

\begin{tabular}{|l|c|c|c|}
\hline Measurements, Inches & Average Loss & Median Loss & std dev \\
\hline Neck_Full & -0.65 & -0.49 & 1.09 \\
\hline Bust_Full & -2.15 & -1.96 & 1.97 \\
\hline Bust_Full(Contoured) & -2.27 & -2.00 & 2.12 \\
\hline Right_Biceps & -0.89 & -0.88 & 0.79 \\
\hline Right_Elbow & -0.50 & -0.39 & 0.88 \\
\hline Right_Forearm & -0.39 & -0.31 & 0.83 \\
\hline Left_Biceps & -0.91 & -0.89 & 0.78 \\
\hline Left_Elbow & -0.49 & -0.55 & 1.03 \\
\hline Left_Forearm & -0.38 & -0.39 & 0.70 \\
\hline Waist_Full & -3.03 & -2.66 & 1.72 \\
\hline Hips_Full & -3.14 & -3.06 & 1.51 \\
\hline Seat_Full & -3.20 & -2.98 & 1.55 \\
\hline Abdomen_Full & -3.12 & -3.11 & 2.49 \\
\hline Thigh_Left & -1.41 & -1.46 & 1.02 \\
\hline Thigh_Right & -1.52 & -1.47 & 1.19 \\
\hline Calf_Left & -0.66 & -0.61 & 0.76 \\
\hline Calf_Right & -0.56 & -0.60 & 0.94 \\
\hline Knee_Left & -0.73 & -0.61 & 1.13 \\
\hline Knee_Right & -0.72 & -0.58 & 1.22 \\
\hline & & & \\
\hline Torso Height cm & -0.32 & 0.00 & 1.95 \\
\hline Torso Volume cc & -7640.32 & -7381.95 & 4116.59 \\
\hline Torso Surface Area & -457.95 & -410.70 & 334.67 \\
\hline BariPlex & 0.52 & 0.51 & 0.33 \\
\hline TVSA Ratio & -0.52 & -0.47 & 0.28 \\
\hline Weight & -22.73 & -21.50 & 9.78 \\
\hline & & & \\
\hline & & & \\
\hline
\end{tabular}

Table 7: Three to Six Month Postoperative Measurements Changes 
The average weight loss for this time period was 24 pounds. This is another very diverse set of data assembled from a different population of post-operative female individuals. The averages and the medians for each measurement appear to be well behaved. Comparing the standard deviations from Table 7 to Table 6 , the 3 month changes indicates a general tightening. The exceptions here are measurements pertaining to the waist, abdomen and seat, as well as the calves and knees. Again, the changes in Torso Height between the 3 month and 6 month time periods are minimal.

Table 8 displays the changes to a population of female individuals between their 6 month postoperative scan and their 1 year postoperative scan. The sample size for this group was composed of 70 females.

\begin{tabular}{|l|c|c|c|}
\hline Measurements, Inches & Average Loss & Median Loss & std dev \\
\hline Neck_Full & -0.63 & -0.45 & 1.92 \\
\hline Bust_Full & -1.11 & -0.95 & 1.67 \\
\hline Bust_Full(Contoured) & -1.19 & -0.79 & 1.76 \\
\hline Right_Biceps & -0.40 & -0.42 & 0.80 \\
\hline Right_Elbow & -0.20 & -0.18 & 0.66 \\
\hline Right_Forearm & -0.27 & -0.19 & 0.77 \\
\hline Left_Biceps & -0.38 & -0.38 & 0.85 \\
\hline Left_Elbow & -0.15 & -0.21 & 0.76 \\
\hline Left_Forearm & -0.27 & -0.18 & 0.78 \\
\hline Waist_Full & -1.05 & -1.01 & 1.87 \\
\hline Hips_Full & -1.09 & -0.76 & 1.63 \\
\hline Seat_Full & -1.11 & -0.91 & 1.69 \\
\hline Abdomen_Full & -0.82 & -0.31 & 2.19 \\
\hline Thigh_Left & -0.61 & -0.40 & 1.09 \\
\hline Thigh_Right & -0.63 & -0.46 & 1.15 \\
\hline Calf_Left & -0.32 & -0.28 & 0.50 \\
\hline Calf_Right & -0.36 & -0.38 & 0.44 \\
\hline Knee_Left & -0.34 & -0.37 & 0.69 \\
\hline Knee_Right & -0.34 & -0.38 & 0.77 \\
\hline & & & \\
\hline Torso Height cm & -0.39 & 0.00 & 2.03 \\
\hline Torso Volume cc & -3060.39 & -2402.65 & 5448.04 \\
\hline Torso Surface Area & -191.67 & -163.25 & 402.75 \\
\hline BariPlex & 0.24 & 0.20 & 0.30 \\
\hline TVSA Ratio & -0.23 & -0.19 & 0.29 \\
\hline Weight & -9.06 & -7.50 & 11.69
\end{tabular}

Table 8: Six Month to 1 year Postoperative Measurement Changes

The average weight loss for this final period was only 9 pounds, but the standard deviation is fairly wide indicating that many of the individuals in the sample population lost more weight and some in the sample population actually gained several pounds or their weight was unchanged from their 6 month postoperative scan date. 
Table 9 displays the composite average changes for each measurement and their cumulative total.

\begin{tabular}{|c|c|c|c|c|}
\hline & 3 Month & 6 Month & 1 Year & \\
\hline Measurements, Inches & Average Loss & Average Loss & Average Loss & Total Loss \\
\hline Neck_Full & -1.80 & -0.65 & -0.63 & -3.08 \\
\hline Bust_Full & -5.14 & -2.15 & -1.11 & -8.40 \\
\hline Bust_Full(Contoured) & -5.25 & -2.27 & -1.19 & -8.72 \\
\hline Right_Biceps & -1.77 & -0.89 & -0.40 & -3.05 \\
\hline Right Elbow & -1.01 & -0.50 & -0.20 & -1.70 \\
\hline Right_Forearm & -1.14 & -0.39 & -0.27 & -1.80 \\
\hline Left_Biceps & -1.74 & -0.91 & -0.38 & -3.03 \\
\hline Left_Elbow & -1.08 & -0.49 & -0.15 & -1.72 \\
\hline Left_Forearm & -1.10 & -0.38 & -0.27 & -1.75 \\
\hline Waist_Full & -5.83 & -3.03 & -1.05 & -9.91 \\
\hline Hips_Full & -5.98 & -3.14 & -1.09 & -10.20 \\
\hline Seat_Full & -5.96 & -3.20 & -1.11 & -10.28 \\
\hline Abdomen_Full & -6.33 & -3.12 & -0.82 & -10.27 \\
\hline Thigh_Left & -3.08 & -1.41 & -0.61 & -5.09 \\
\hline Thigh_Right & -3.16 & -1.52 & -0.63 & -5.31 \\
\hline Calf_Left & -1.27 & -0.66 & -0.32 & -2.26 \\
\hline Calf_Right & -1.30 & -0.56 & -0.36 & -2.22 \\
\hline Knee_Left & -1.33 & -0.73 & -0.34 & -2.40 \\
\hline Knee_Right & -1.39 & -0.72 & -0.34 & -2.46 \\
\hline Torso Height $\mathrm{cm}$ & -0.39 & -0.32 & -0.39 & NA \\
\hline Torso Volume cc & -15939.23 & -7640.32 & -3060.39 & -26639.94 \\
\hline Torso Surface Area & -907.11 & -457.95 & -191.67 & -1556.72 \\
\hline BariPlex & 0.82 & 0.52 & 0.24 & 1.58 \\
\hline TVSA Ratio & -0.97 & -0.52 & -0.23 & -1.72 \\
\hline Weight & -50.87 & -22.73 & -9.06 & -82.66 \\
\hline
\end{tabular}

Table 9: Composite Periodic Measurement Changes and Cumulative Measurement Change

Table 9 indicates a gradual tapering of measurement changes and weight loss. Note that the Torso Height is consistent for each scan interval. The actual median for the Torso Height change was 0 , as noted in the previous tables. Collectively, the independent sample populations lost an average of 83 pounds 1 year after surgery. Associated with that weight loss were commensurate changes in Torso Volume, Torso Surface Area and circumferential measurements.

Figure 4 depicts the information within the Table 9 in chart form. The chart displays the longitudinal changes for the circumferential measurements. 


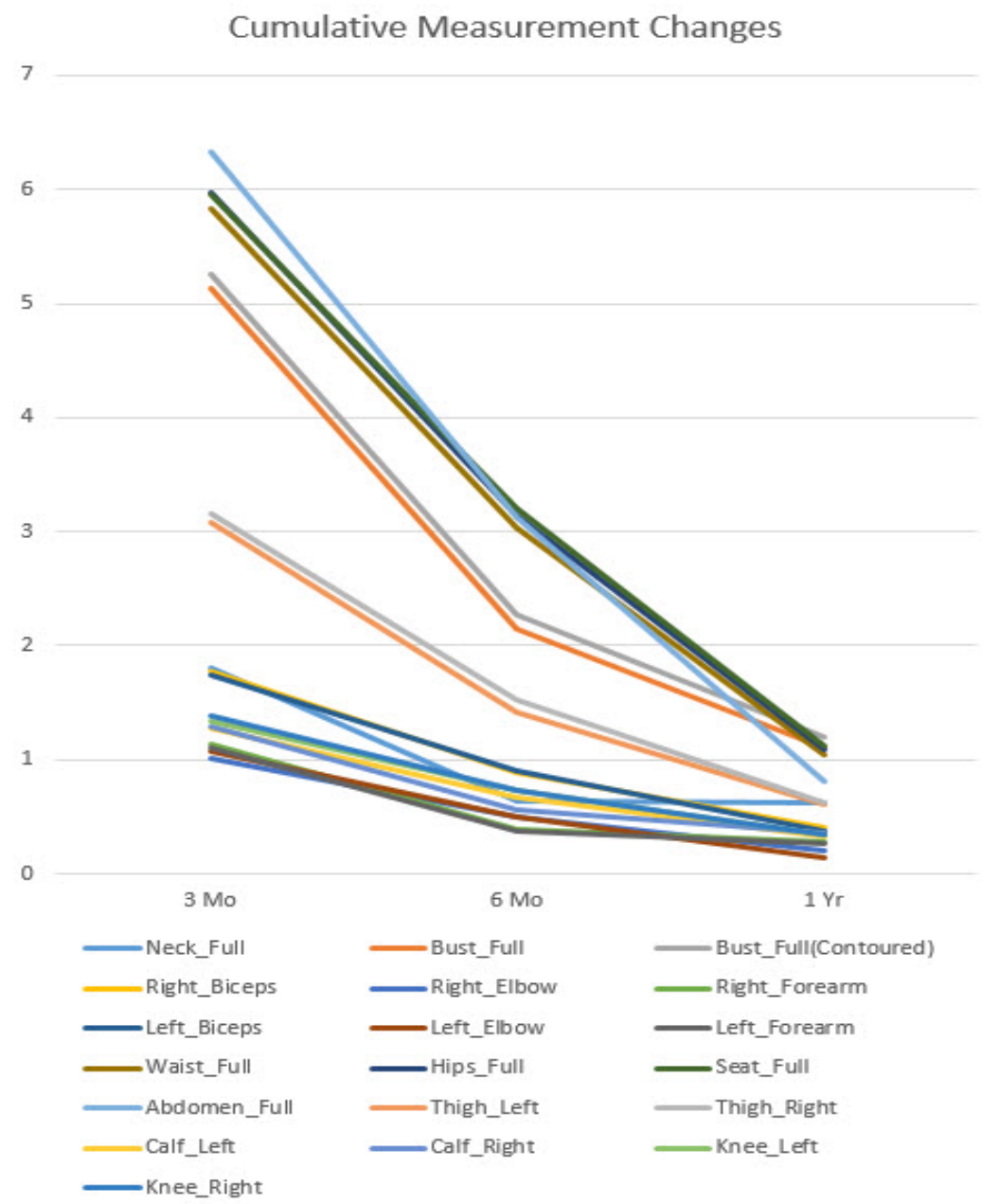

Figure 4. Cumulative Circumferential Measurement Changes at 3, 6 month and 1 year intervals

Examination of the chart above and the cumulative measurement change Table 9 indicates that the individuals lost the most weight and had the largest percentage decrease of circumferential measurements during the first 3 month period of surgery. Each measurement period had less dramatic change. It should be observed that the near straight line on the chart towards the bottom represents the neck measurement. Many of the individuals scanned had portions of their hair covering their neck. In general commercial practice, the neck measurement is usually disregarded as part of the individual's Storybook if such a situation is encountered. 
The three charts presented in Figure 5 depict the curves that reflect longitudinal weight loss, Torso Volume loss and Torso Surface Area loss.
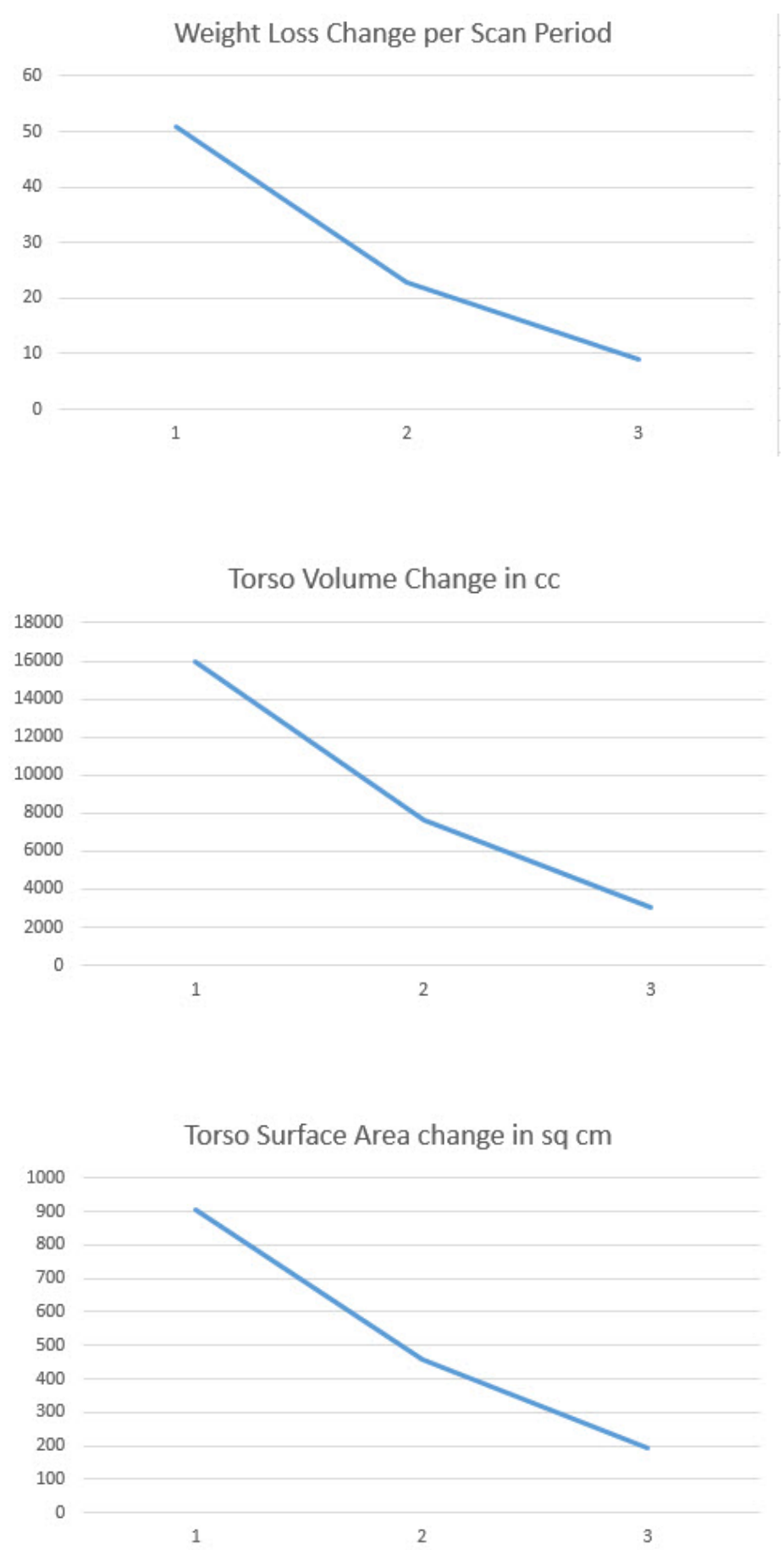

Figure 5. Charts comparing Weight Loss to Changes in Torso Volume and Torso Surface Area

Close examination of Figure 5 shows that the curves follow similar trajectories, but the downward slope of each curve is slightly different.

We now return to the set of preoperative females with the initial conditions found in Table 5 to examine overall changes instead of the relative changes between scan intervals. 
It has been noted how Excess Weight and \% Excess Weight are determined, and that one measure of a successful outcome for a gastric bypass or sleeve bariatric surgery procedure is that the individual achieves around $75 \%$ Excess Weight loss in a period of 1 year after surgery.

A premise made in this analysis posits that if one can determine the Excess Weight and \% Excess Weight of a morbidly obese individual, the \% Excess Weight factor might be able to be applied to their Torso Volume and Torso Surface Area initial values. The same might be true as well for the Bariplex and TVSA Ratio.

Table 10 represents the \% Excess Weight factor as a multiplier to these calculations. Shown in Table 10 are the resulting statistics for the initial conditions of the "Overall Change Group."

\begin{tabular}{|l|c|c|c|c|c|c|c|c|}
\hline & $\begin{array}{c}\text { Initial Torso } \\
\text { Volume }\end{array}$ & $\begin{array}{c}\text { Excess } \\
\text { Torso } \\
\text { Volume }\end{array}$ & $\begin{array}{c}\text { Initial } \\
\text { Torso } \\
\text { Surface } \\
\text { Area }\end{array}$ & $\begin{array}{c}\text { Excess } \\
\text { Torso } \\
\text { Surf Area }\end{array}$ & $\begin{array}{c}\text { Initial } \\
\text { BariPlex }\end{array}$ & $\begin{array}{c}\text { Excess } \\
\text { BariPlex }\end{array}$ & $\begin{array}{c}\text { Initial } \\
\text { TVSA }\end{array}$ & $\begin{array}{c}\text { Excess } \\
\text { TVSA }\end{array}$ \\
\hline Average & 80701.85 & 39197.52 & 8574.77 & 4118.76 & 7.28 & 3.43 & 9.31 & 4.45 \\
\hline Median & 78156.10 & 35706.48 & 8468.30 & 3888.62 & 7.28 & 3.50 & 9.28 & 4.41 \\
\hline Std.Dev. & 19105.59 & 15772.79 & 1185.57 & 1188.70 & 0.56 & 0.44 & 0.84 & 1.04 \\
\hline MIN & 57483.70 & 20877.16 & 6791.30 & 2466.49 & 6.32 & 2.57 & 8.01 & 3.06 \\
\hline MAX & 160465.80 & 108450.40 & 13357.80 & 9027.84 & 8.45 & 4.67 & 12.01 & 8.12 \\
\hline
\end{tabular}

Table 10: Initial Values for Measurements as multiplied by the "\% Excess Weight" factor

At the end of the 1 year period this sample female population achieved the weight loss characteristics set forth in Table 11.

\begin{tabular}{|c|c|c|c|c|c|}
\hline & Initial Weight & $\begin{array}{c}\text { Excess } \\
\text { Weight }\end{array}$ & $\begin{array}{c}\text { \% Excess } \\
\text { Weight }\end{array}$ & $\begin{array}{c}\text { Weight Lost } \\
\text { 1 Year }\end{array}$ & $\begin{array}{c}\text { \%Excess } \\
\text { Weight Loss }\end{array}$ \\
\hline Average & 267 & 129 & .47 & -88 & .70 \\
\hline Median & 260 & 123 & .47 & -79 & .71 \\
\hline Std. Dev & 48 & 45 & .07 & 28.1 & .16 \\
\hline MIN & 201 & 72 & .34 & -49 & .43 \\
\hline MAX & 472 & 319 & .68 & -172 & 1.01 \\
\hline
\end{tabular}

Table 11: Results 1 year after surgery using traditional "\% Excess Weight Loss" of the "Overall Change Group"

The average weight loss for this group was 88 pounds, with a large variation given the range of individual initial body weights. Collectively, they achieved a "\% Excess Weight Loss" of $70 \%$, fairly close to the $75 \%$ benchmark at the 1 year after surgery interval.

Further, the group showed wide individual variability. The minimum \% Excess Weight Loss over a 1 year period was $43 \%$, and the maximum \% Excess Weight Loss was $101 \%$. The latter occurred in two instances.

Table 11 tells us no new information. This is an existing technique widely used in practice. However, using the 3D body scanner to scan morbidly obese individuals prior to and after the surgical procedure on a repetitive basis not only yields changes to common circumferential measurements but also multidimensional information that can be tracked longitudinally.

The following are series of tables that present the overall measurement changes for initial conditions set forth in Table 10.

Table 12 contains the "Overall Change Group's" information for changes in Torso Volume.

\begin{tabular}{|c|c|c|c|c|}
\hline & $\begin{array}{c}\text { Overall Torso } \\
\text { Volume Change }\end{array}$ & $\begin{array}{c}\text { 1 Year Torso } \\
\text { Volume Reading }\end{array}$ & $\begin{array}{c}\text { \% Torso Volume } \\
\text { Change }\end{array}$ & $\begin{array}{c}\% \text { Excess Torso } \\
\text { Volume Loss }\end{array}$ \\
\hline Average & -28841.22 & 51860.63 & -0.35 & -0.74 \\
\hline Median & -25421.05 & 50359.15 & -0.34 & -0.72 \\
\hline Std. Dev. & 2.21 & 12511.66 & 10541.18 & 0.09 \\
\hline MIN & -4.00 & -69208.60 & 36531.30 & -0.52 \\
\hline MAX & 4.00 & -11847.60 & 91257.20 & -0.16 \\
\hline
\end{tabular}

Table 12: "Overall Change Group" Changes in Torso Volume and \% Excess Torso Volume 
Table 13 contains overall change information for this group's Torso Surface Area.

\begin{tabular}{|c|c|c|c|c|}
\hline & $\begin{array}{c}\text { Overall Torso } \\
\text { Surface Area } \\
\text { Change }\end{array}$ & $\begin{array}{c}1 \text { Year Torso } \\
\text { Surface Area } \\
\text { Reading }\end{array}$ & $\begin{array}{c}\text { \% Torso Surface } \\
\text { Area Change }\end{array}$ & $\begin{array}{c}\text { \% Excess Torso } \\
\text { Surface Area } \\
\text { Loss }\end{array}$ \\
\hline Average & -1663.16 & 6911.61 & -0.19 & -0.40 \\
\hline Median & -1499.95 & 6876.45 & -0.18 & -0.40 \\
\hline Std. Dev. & 628.69 & 844.14 & 0.05 & 0.11 \\
\hline MIN & -3457.60 & 5738.40 & -0.32 & -0.65 \\
\hline MAX & -855.20 & 9900.20 & -0.11 & -0.22 \\
\hline
\end{tabular}

Table 13: "Overall Change Group" Changes in Torso Surface Area and \% Excess Torso Surface Area

Table 14 and Table 15 contain overall change information for the group's BariPlex and TVSA Ratio.

\begin{tabular}{|c|c|c|c|c|}
\hline & $\begin{array}{c}\text { Overall BariPlex } \\
\text { Change }\end{array}$ & $\begin{array}{c}\text { 1 Year BariPlex } \\
\text { Reading }\end{array}$ & $\begin{array}{c}\text { \% BariPlex } \\
\text { Change }\end{array}$ & $\begin{array}{c}\text { \% Excess } \\
\text { BariPlex } \\
\text { GAIN }\end{array}$ \\
\hline Average & 1.84 & 9.12 & 0.26 & 0.55 \\
\hline Median & 1.77 & 9.15 & 0.25 & 0.48 \\
\hline Std. Dev. & 0.63 & 0.69 & 0.10 & 0.22 \\
\hline MIN & 0.45 & 6.91 & 0.07 & 0.16 \\
\hline MAX & 3.32 & 10.39 & 0.51 & 1.26 \\
\hline
\end{tabular}

Table 14: "Overall Change Group" Changes in BariPlex and \% Excess Bariplex

\begin{tabular}{|c|c|c|c|c|}
\hline & $\begin{array}{c}\text { Overall TVSA } \\
\text { Ratio Change }\end{array}$ & $\begin{array}{c}\text { 1 Year TVSA } \\
\text { Ratio Reading }\end{array}$ & $\begin{array}{c}\text { \% TVSA Ratio } \\
\text { Change }\end{array}$ & $\begin{array}{c}\text { \% Excess TVSA } \\
\text { Ratio Loss }\end{array}$ \\
\hline Average & -1.85 & 7.46 & -0.20 & -0.42 \\
\hline Median & -1.76 & 7.47 & -0.20 & -0.42 \\
\hline Std. Dev. & 0.72 & 0.62 & 0.07 & 0.14 \\
\hline MIN & -3.48 & 6.35 & -0.33 & -0.78 \\
\hline MAX & -0.52 & 9.22 & -0.06 & -0.13 \\
\hline
\end{tabular}

Table 15: "Overall Change Group" Changes in TVSA Ratio and \% Excess TVSA Ratio

Table 16 summarizes the \% Excess changes of the initial conditions, including \% Excess Weight Loss for the "Overall Change Group."

\begin{tabular}{|c|c|c|c|c|c|}
\hline & $\begin{array}{c}\text { \%Excess } \\
\text { Weight Loss }\end{array}$ & $\begin{array}{c}\text { \% Excess } \\
\text { Torso } \\
\text { Volume Loss }\end{array}$ & $\begin{array}{c}\text { \% Excess } \\
\text { Torso } \\
\text { Surface Area } \\
\text { Loss }\end{array}$ & $\begin{array}{c}\text { \% Excess } \\
\text { BariPlex } \\
\text { GAIN }\end{array}$ & $\begin{array}{c}\text { \% Excess } \\
\text { TVSA Ratio } \\
\text { Loss }\end{array}$ \\
\hline Average & $\mathbf{. 7 0}$ & $\mathbf{- 0 . 7 4}$ & $\mathbf{- 0 . 4 0}$ & $\mathbf{0 . 5 5}$ & $\mathbf{- 0 . 4 2}$ \\
\hline Median & .71 & -0.72 & -0.40 & 0.48 & -0.42 \\
\hline Std. Dev & .16 & 0.09 & 0.11 & 0.22 & 0.14 \\
\hline MIN & .43 & -0.52 & -0.65 & 0.16 & -0.78 \\
\hline MAX & 1.01 & -0.16 & -0.22 & 1.26 & -0.13 \\
\hline
\end{tabular}

Table 16: \% Excess Weight Loss and Multidimensional \% Excess Loss

Table 16 presents entirely new information about \% Excess conditions alongside the current "\% Excess Weight Loss" technique. It is a summary multidimensional \% Excess chart that reflects a set of female bariatric individuals that were scanned preoperatively and scanned at 1 year postoperatively. It is important to note that as individuals lose Torso Volume and Torso Surface area, the BariPlex function will show an increase. This is because the fixed torso height is divided product of the Torso Volume/Torso Surface Area, which decreases as the individual loses size.

As 3D body scanning becomes more prevalent in the medical world, and in bariatric and weight loss practices in general, the values in the multidimensional columns could become another reference standard. 
The final area of interest is a comparison of the circumferential measurement statistics gathered from the group of female individuals that comprise the "Overall Change Group" and the cumulative changes from the other groups as summarized in the "Total Loss" column in Table 17. Also included are the cumulative multidimensional change information and weight loss.

\begin{tabular}{|c|c|c|}
\hline & Cumulative & Overall Change Group \\
\hline Measurements, Inches & Total Loss Average & Total Loss Average \\
\hline Neck_Full & -3.08 & -4.37 \\
\hline Bust_Full & -8.40 & -9.72 \\
\hline Bust_Full(Contoured) & -8.72 & -10.13 \\
\hline Right_Biceps & -3.05 & -3.44 \\
\hline Right_Elbow & -1.70 & -2.11 \\
\hline Right_Forearm & -1.80 & -1.72 \\
\hline Left_Biceps & -3.03 & -3.55 \\
\hline Left_Elbow & -1.72 & -2.16 \\
\hline Left_Forearm & -1.75 & -1.89 \\
\hline Waist_Full & -9.91 & -11.78 \\
\hline Hips_Full & -10.20 & -11.45 \\
\hline Seat_Full & -10.28 & -11.44 \\
\hline Abdomen_Full & -10.27 & -12.25 \\
\hline Thigh_Left & -5.09 & -6.29 \\
\hline Thigh_Right & -5.31 & -6.35 \\
\hline Calf_Left & -2.26 & -2.86 \\
\hline Calf_Right & -2.22 & -2.88 \\
\hline Knee_Left & -2.40 & -3.13 \\
\hline Knee_Right & -2.46 & -3.14 \\
\hline Torso Height $\mathrm{cm}$ & 0.00 & 0.00 \\
\hline Torso Volume cc & -26639.94 & -28841.22 \\
\hline Torso Surface Area & -1556.72 & -1663.16 \\
\hline BariPlex & 1.58 & 1.84 \\
\hline TVSA Ratio & -1.72 & -1.85 \\
\hline Weight & -82.66 & -88.17 \\
\hline
\end{tabular}

Table 17: Comparision of Circumferential Measurement Changes, Weight and Multidimensional Information

Table 17 indicates directional similarities between the independent grouping cumulative totals and the "Overall Change Group." The "Overall Change Group of 50 females had two "outliers" that weighed 425 pounds or more. If these two entries were deleted, the "Overall Change Group" would have had very similar results to the cumulative totals that had a larger number of independent samples. Regardless, the trend between these two groups were similar.

The "\% Excess Weight" factor was also used to determine "Excess Circumference" and "\% Excess Circumferences." Calculations were made on the overall change group for average $\%$ circumferential measurements lost, and average \% excess circumferential measurements lost. Table 18 below summarizes these findings. 
Average \% Loss Median \% Loss \% Std. Dev. Ave \% Excess Loss Median \% Excess Loss \% Excess Loss Std Dev

\begin{tabular}{|c|c|c|c|c|c|c|}
\hline & & & & & & \\
\hline \multicolumn{7}{|l|}{ Measurements, Inches } \\
\hline Neck_Full & $20 \%$ & $19 \%$ & $10 \%$ & $-41 \%$ & $-41 \%$ & $19 \%$ \\
\hline Bust_Full & $18 \%$ & $18 \%$ & $7 \%$ & $-36 \%$ & $-37 \%$ & $15 \%$ \\
\hline Right_Biceps & $19 \%$ & $19 \%$ & $11 \%$ & $-39 \%$ & $-39 \%$ & $25 \%$ \\
\hline Right_Elbow & $15 \%$ & $16 \%$ & $7 \%$ & $-30 \%$ & $-31 \%$ & $14 \%$ \\
\hline Left_Elbow & $15 \%$ & $16 \%$ & $7 \%$ & $-31 \%$ & $-30 \%$ & $15 \%$ \\
\hline Left_Forearm & $14 \%$ & $14 \%$ & $8 \%$ & $-29 \%$ & $-30 \%$ & $16 \%$ \\
\hline Waist_Full & $23 \%$ & $22 \%$ & $7 \%$ & $-47 \%$ & $-48 \%$ & $16 \%$ \\
\hline Hips_Full & $19 \%$ & $19 \%$ & $6 \%$ & $-40 \%$ & $-42 \%$ & $15 \%$ \\
\hline Calf_Left & $14 \%$ & $14 \%$ & $5 \%$ & $-30 \%$ & $-28 \%$ & $12 \%$ \\
\hline Calf_Right & $15 \%$ & $14 \%$ & $5 \%$ & $-30 \%$ & $-28 \%$ & $13 \%$ \\
\hline Knee_Left & $15 \%$ & $14 \%$ & $7 \%$ & $-31 \%$ & $-29 \%$ & $17 \%$ \\
\hline Knee_Right & $15 \%$ & $14 \%$ & $8 \%$ & $-31 \%$ & $-31 \%$ & $18 \%$ \\
\hline
\end{tabular}

Table 18: "Overall Change Group" Average \% Circumferential and Average \% Excess Circumferential Loss

\section{Discussion}

The intriguing data sets presented above give multidimensional insight as to how the body changes when undergoing massive weight loss.

Unidimensional circumferential measurements percentage losses seem to indicate an average, even uniform loss pattern over such a diverse set of individuals. Both the average and median circumferential losses are nearly identical, with fairly tight standard deviations.

The same approach to calculate excess weight was applied to develop "Excess Circumferential Measurements." That is, once the determination for "\% Excess Weight" was found for the individual, it was then applied to each circumferential measurement. For instance, if someone was determined to have $48 \%$ excess weight (.48), the initial circumferential measurement was multiplied by that factor. "\% Excess Circumferential Measurement" was then found by calculating the total change to that measurement at the end of the 1 year interval and then dividing by the value generated by multiplying the "\% Excess Weight" factor by the initial circumferential measurement.

Both the average "\% Excess Circumferential Loss" and the median "\% Excess Circumferential Loss" were very similar, however the "\% Excess Circumferential Loss" standard deviations were much wider than the standard deviations for just the average circumferential loss. This may reflect the various range of actual individual "\% Excess Weight Loss" in the sample group during the 1 year interval (refer to Table 11 for the minimum and maximum).

This might also reflect that "Average \% Loss" may be a better way of tracking excess weight loss than average "\% Excess Loss", given the wide disparity between their standard deviations.

To ensure that the torso volume and torso surface area calculations were consistent between each individual's longitudinal scan series, manual adjustments of the "Crotchpoint" location often had to be performed. This is a crucial point. Consistent location of the "Crotchpoint" measurement has a direct influence on the torso height, which in turn has a direct influence on both the torso volume and torso surface area calculations. These calculations determine the TVSA Ratio and the Bariplex.

Can we now tell the morbidly obese female individual more information than just to expect the $75 \%$ "Excess Weight Loss" that she might achieve at the end of 1 year after bariatric surgery? 
If these statistics presented within the charts and tables of this paper are any indication, we may be to able scan her prior to her procedure and tell her with a certain level of confidence that in addition to the reduction in weight she can also look forward to:

A $23 \%$ reduction in your waist measurement.

A $19 \%$ reduction in your hips measurement.

A $35 \%$ reduction in your torso volume.

A $19 \%$ reduction in your torso surface area.

This, among other average measurements.

We may also be able to present her with a fairly accurate predictive model of her appearnce around 1 year after weight loss surgery prior to the actual weight loss surgical procedure to be performed. This could be used as a behavioral, tracking and motivation tool, or assist in Body Image Analysis and Body Image Dissatisfaction research.

But that, Dear Reader, is a subject to be presented in another paper.

\section{References}

1. Metropolitan Life Insurance Company. New weight standards for men and women. Stat Bull Metropol Life Insur Co 1959;40:1-4.

2). http://usmilitary.about.com/od/army///blweightfemale.htm

3). http://www.am-i-fat.com/weight tables women.html

4). http://bariatrictimes.com/measuring-success-a-comparison-of-weight-loss-calculations/

5) Theory and Practical Steps to Introducing a new 3D Public Health Indicator to replace BMI Using Existing Population-based Multidimensional Reference Measurement Sets. David B. STEFAN, Stephen D. WOHLGEMUTH, David A. GILBERT. Proc. of 5th Int. Conf. on 3D Body Scanning Technologies, Lugano, Switzerland, 2014, pp. 299-312, DOI: 10.15221/14.299. 